\title{
Signal Amplitude
}

National Cancer Institute

\section{Source}

National Cancer Institute. Signal Amplitude. NCI Thesaurus. Code C112416.

A measurement of the height of the signal such as a magnetic pulse. 